\title{
COMMUNITY'S AWARENESS ABOUT INTESTINAL SCHISTOSOMIASIS AND THE PREVALENCE OF INFECTION IN TWO ENDEMIC LOCALITIES OF ETHIOPIA
}

\author{
Mengistu Legesse ${ }^{* 1}, M S c$, Chelsea R. Jones ${ }^{2}, B S c, S a r i t a ~ K . ~ S i n g h{ }^{3}, B S c$, Berhanu Erko ${ }^{1}, M S c$, \\ Yalemtsehay Mekonnen ${ }^{1}, \mathrm{PhD}$
}

\begin{abstract}
BACKGROUND: Intestinal schistosomiasis caused by Schistosoma mansoni(S. mansoni) infection is a widely distributed disease in several localities of Ethiopia. However, very limited information is available on the level of community's awareness about the disease. The aim of this study was to assess community's awareness about intestinal schistosomiasis as well as the prevalence of the disease in two rural communities of Ethiopia.

METHODS: In June 2004, a cross-sectional study on awareness and prevalence of intestinal schistosomiasis was conducted in rural communities living in Dudicha and Shesha Kekel peasant associations.

RESULTS: Among 176 respondents from Dudicha, only 45 (25.6\%) individuals heard about Bilharzia. Similarly, among 241 respondents from Shesha Kekel only 78 (32.4\%) subjects heard about Bilharzia. The proportion of males who heard about Bilharzia was higher than that of females both in Dudicha $(38 \%$ vs $7 \%$, p< 0.001$)$ and Shesha Kekel (51.6\% vs 20\%, p<0.001). There was no significant difference in level of awareness about schistosomiasis between the two communities (Dudicha, 25. 6\% vs Shesha Kekel, 32.4\%, p> 0.05). Only 1(0.6\%) individual from Dudicha and 6(2.5\%) participants from Shesha Kekel had knowledge of the intermediate host. The prevalence of the disease was $43.2 \%$ in Dudicha and $31.6 \%$ in Shesha Kekel. The prevalence of infection was higher in males than in females in Dudicha community (56.7\% vs $21.5 \%, p<0.05)$.

CONCLUSION: Although the disease was prevalent in the two sites, majority of the people had no awareness about schistosomiasis. Therefore, provision of health education could raise community's awareness of schistosomiasis in such endemic areas of the country.
\end{abstract}

KEYWORDS: Intestinal schistosomiasis, community's awareness, prevalence, Ethiopia

\section{INTRODUCTION}

As the results of irrigation schemes, population increment and movement, low socio-economic status, schistosomiasis (Bilharzia) continues to be a major public health and socio-economic problem for several millions of people living in the rural areas of the tropics (1-3). In 1993, the World Health Organization (WHO) estimated that at least 200 million people are infected and about 600 million people are at risk of infection with schistosome parasites in more than 76 endemic countries (4).

Control of the disease is aiming at reducing morbidity and mortality using chemotherapy rather than preventing infection itself (5). However, a number of studies indicated the importance of having detailed information on what the community knows about the infection and socio-cultural factors that influence community's
*Corresponding author: Mengistu Legesse, P.O. Box 1176, Institute of Pathobilogy, Addis Fax:00251-1-755296/550655,e-mail:dlegessem@yahoo.com

perception about the disease, to make the control of schistosomiasis more effective and sustainable in endemic areas (6-12).

In Ethiopia, a number of epidemiological studies showed that intestinal schistosomiasis due to $S$. mansoni infection is a widely distributed in several localities of the country with varying magnitudes of prevalence as high as $90 \%$ in school children (13-18). On the other hand, very limited information is available on the assessment of community's perception and knowledge about the source of infection, mode of transmission, prevention and control of schistosomiasis (19).

The present study was, therefore, undertaken to assess the level of community's awareness about intestinal schistosomiasis, its source of infection, mode of

\footnotetext{
${ }^{1}$ Institute of Pathobiology , Addis Ababa University, P.O.Box 1176, Addis Ababa, Ethiopia

${ }^{2}$ Howard University, Department of Biology, Washington, DC20059

${ }^{3}$ New York University, 22 Washington Square North, New Yourk, NY 10011, USA
} 
methods in two rural communities living in intestinal schistosomiasis endemic areas of Ethiopia.

\section{MATERIALS AND METHODS}

In June 2004, study on awareness about schistosomiasis and parasitological survey were conducted in two rural communities living in endemic localities, Dudicha and Shesha Kekel peasant associations $(13-15,17,20)$.

Dudicha is a peasant association found in Ziway Dugida Bora district. It is located on the Southeast of Lake Ziway shore at an altitude of 1657 meters above sea level. It had about 740 households and most of the inhabitants were engaged in mixed farming, crop production and rearing livestock, mainly cattle and goats. Tomato, onion, maize and haricot beans are widely produced in the area using irrigation. All of the inhabitants were living under similar poor environmental sanitation and low socio-economic status. They use lake water for everyday activities such as washing, bathing and drinking. There were one health center and several private clinics in Ziway Town, which provide health service for the people of Dudicha.

Shesha Kekel is a peasant association of Wondo Genet district in Southern Ethiopia. It is located at $270 \mathrm{~km}$ south of Addis Ababa at an altitude of about 1800 meters above sea level. It had about 1175 households and most of the inhabitants earn their living from mixed agriculture. Enset (Ensete ventricosum) and maize are the principal food crops of the area. Sugar cane and chat (Catha edulis) are the principal cash crops of the area produced using traditional irrigation method. The people in the area depend on river/stream water for everyday activities such as washing, bathing and drinking. There were one health post and two private clinics in the study area.

After obtaining information on the number of households in each of the study area, about $25 \%$ of the households from each study community, 185 and 294 households in Dudicha and in Shesha Kekel, respectively were selected using systematic sampling. Then, the heads of the households or the eldest in their absence (male or female, member of the household and older 15 years) were considered for the interview. Each interviewee was asked about Bilharzia, its source of infection and mode of transmission, symptoms, prevention and treatment by his/her own local language by trained data collectors selected from the study areas.

Open and closed-ended questions were prepared in English, pre-tested and then translated into Amharic and finally re-translated into the local language for the interview. To confirm whether or not Bilharzia has another local name, health workers in the study areas and data collectors were asked and they confirmed that the disease is only known by the name Bilharzia. During the interview, care was taken not to confuse Bilharzia with other diseases like amoebiasis and giardiasis. A continuous supervision was made to ensure the quality of the data.

In order to assess the relationship between awareness about the disease and the prevalence of infection, each interviewee was requested to provide fresh stool sample. Accordingly, 169 and 234 stool samples were collected from Dudicha and Shesha Kekel, respectively. The samples were processed by the Kato technique (21). Single slide was prepared for each sample and examined on the spot for ova of $S$. mansion and other intestinal helminths using light microscope.

Data were tabulated and analyzed using SPSS for Windows by considering different categories in the questionnaires as well as the results of parasitological survey. Chi-square test was used to compare proportion of awareness.

The aim of the study was explained to the responsible bodies at district and community levels as well as to the study population to obtain verbal consent. Those individuals who were found positive for $S$. mansoni and other intestinal helminths were treated with praziquantel and albendazole, respectively. At the end of the interview, information about Bilharzia, its source of infection, mode of transmission, methods of prevention and control were explained to the participants and community leaders using posters.

\section{RESULTS}

A total of $417(87.1 \%)$ individuals, 176 from Dudicha (age range 15-70 years) and 241 from Shesha Kekel (age range 15-80 years) were interviewed. Among the selected households, 9(4.8\%) households in Dudiha and $53(18.0 \%)$ in Shesha Kekel were not interviewed, as the heads of the household or the eldest were refused to participate. Seventy nine (44.9\%) of the respondents in Dudicha and 106 (44.0\% in Shesha Kekel) were illiterate. Most of the respondents were farmers $(78.4 \%$ in Dudicha and $89.6 \%$ in Shesha Kekel) (Table 1). 
Table 1. Educational status and occupation of respondents, Dudich and Shesha Kekel communities, June 2004

\begin{tabular}{lllllll}
\hline \multirow{2}{*}{ Variables } & \multicolumn{5}{c}{ Dudicha } & \multicolumn{3}{l}{ Shesha Kekel } \\
\cline { 2 - 7 } & $\begin{array}{c}\text { Male(\%) } \\
\mathrm{n}=105\end{array}$ & $\begin{array}{c}\text { Female(\%) } \\
\mathrm{n}=71\end{array}$ & $\begin{array}{c}\text { Total }(\%) \\
\mathrm{n}=176\end{array}$ & $\begin{array}{c}\text { Male(\%) } \\
\mathrm{n}=91\end{array}$ & $\begin{array}{c}\text { Female(\%) } \\
\mathrm{n}=150\end{array}$ & $\begin{array}{c}\text { Total(\%) } \\
\mathrm{n}=241\end{array}$ \\
\hline $\begin{array}{c}\text { Educational status } \\
\text { Illiterate }\end{array}$ & 19.0 & 83.1 & 44.9 & 30.8 & 52.0 & 44.0 \\
Read/write & 4.8 & 1.4 & 3.4 & 5.5 & 2.7 & 3.7 \\
Primary & 51.4 & 15.5 & 36.9 & 35.2 & 30.0 & 32.0 \\
Secondary & 23.8 & 0 & 14.2 & 28.6 & 15.3 & 20.3 \\
Occupation & & & & & & 89.6 \\
Farmer & 70.5 & 90.1 & 78.4 & 86.8 & 91.3 & 0.8 \\
Merchant & 1.0 & 0 & 0.6 & 2.2 & 0 & 7.9 \\
Student & 26.7 & 9.9 & 19.9 & 8.8 & 7.3 & \\
\hline
\end{tabular}

The majority of the respondents $(76.1 \%$ in Dudicha and $78 \%$ in Shesha Kekel) responded that malaria was a common disease in the areas. Only $2(0.83 \%)$ individuals from Shesha Kekel mentioned Bilharzia. Among 176 respondents from Dudicha, only $45(25.6 \%)$ individuals heard about Bilharzia. Similarly, among 241 respondents from Shesha Kekel, only 78 (32.4\%) subjects heard about Bilharzia. The proportion of males who heard about Bilharzia was higher than that of females both in Dudicha $(38 \%$ vs $7 \%, \mathrm{p}<0.001)$ and Shesha Kekel $(51.6 \%$ vs $20 \%, \mathrm{p}<0.001)$. There was no significant difference in the awareness about the disease between communities in Dudicha and Shesha Kekel (25 6\% vs $32.4 \%, p>0.05)$. The proportion of females who had awareness was higher in Shesha Kekel than in Dudicha $(20.7 \%$ vs $7 \%, p<0.001)$. Among those individuals who heard about Bilharzia, 38(84.4\%) from Dudicha and 70 $(89.7 \%)$ from Shesha Kekel knew that the disease affects children and adults as well as males and females. Three individuals from Shesha Kekel mentioned that only children would catch Bilharzia. Seven individuals from Dudicha and 5 from Shesha Kekel responded that they were not sure that the disease affects all age groups. Of those individuals who had information about Bilharzia, $40(88.9 \%)$ in Dudicha and 56(71.8\%) in Shesha Kekel suggested water as source of infection. When asked how a person can get Bilharzia from water, $28(70 \%)$ of the respondents from Dudicha and 34(60.7\%) from Shesha Kekel mentioned water contact (washing of clothes, fetching, bathing and swimming in river, lake or stream) as means of transmission. Twenty $(44.4 \%)$ of the respondents from Dudicha and 29(51.8\%) from Shesha Kekel responded that the disease can be transmitted both by drinking contaminated water and during bathing or swimming. Almost all of the respondents from the two communities claimed to have frequent water contact (97.7\% in Dudicha and $99.2 \%$ in Shesha Kekel). Of those individuals who mentioned water as the source of infection, the majority (97.5\% from Dudicha and 98.2\% from Shesha Kekel) mentioned that they had frequent water contact for different activities. Only 1 individual from Dudicha and 6 from Shesha Kekel had the knowledge of the intermediate host (Table 2).

Of the total 169 stool samples collected from Dudicha's respondents, 73 (43.2\%) were positive for $S$. mansoni while $74(31.6 \%)$ were positive for $S$. mansoni out of the 234 samples collected from Shesha Kekel's respondents.

The prevalence of infection was higher in males than in females in Dudicha community $(56.7 \%$ vs $21.5 \%, \mathrm{p}<$ $0.05)$. It was also relatively higher in males than in females in Shesha Kekel community $(34.1 \%$ vs $30.1 \%$ ), though, the difference was not statistically significant.

Among individuals who had no information about Bilharzia, 45(36.3\%) from Dudicha and 50 (32.1\%) from Shesha Kekel were positive for $S$. mansoni infection. The prevalence of infection was significantly higher among those who heard about Bilharzia than among who did not hear about it in Dudicha (62.2\% vs 36.3\%, p<0.003).

Among 45 individuals who heard about Bilharzia in Dudicha, $28(62.2 \%)$ were positive for S. mansoni. Among these positive individuals, 3 females and 11 males claimed not to have the disease. Similarly, of those 78 individuals who heard about Bilharzia from Shesha Kekel, 24 (30.8\%) subjects were positive. Of these 
106

July 2009

positive subjects, 4 females and 5 males claimed not to

have Bilharzia.

Table 2. Awareness about Bilharzia, its source of infection, mode of transmission and knowledge of the vector, Dudich and Shesha Kekel communities, 2004.

\begin{tabular}{|c|c|c|c|c|c|c|}
\hline \multirow[b]{2}{*}{ Variables } & \multicolumn{3}{|c|}{ Dudicha } & \multicolumn{3}{|c|}{ Shesha Kekel } \\
\hline & $\begin{array}{c}\text { Male }(\%) \\
n=105\end{array}$ & $\begin{array}{c}\text { Female }(\%) \\
n=71\end{array}$ & $\begin{array}{c}\text { Total }(\%) \\
n=176\end{array}$ & $\begin{array}{c}\text { Male(\%) } \\
n=91\end{array}$ & $\begin{array}{c}\text { Female }(\%) \\
n=150\end{array}$ & $\begin{array}{c}\text { Total(\%) } \\
n=241\end{array}$ \\
\hline \multicolumn{7}{|l|}{ Common diseases in the area } \\
\hline Malaria & $91(86.7)$ & $43(60.6)$ & $134(76.1)$ & $71(78)$ & $117(78)$ & $188(78)$ \\
\hline Giardia, amoeba, AIDS, & $14(13.3)$ & $19(26.8)$ & $33(18.8)$ & $14(15.4)$ & $24(16)$ & $38(15.8)$ \\
\hline typhoid, TB, Ascariasis & 0 & 0 & 0 & $2(2.2)$ & 0 & $2(0.8)$ \\
\hline $\begin{array}{l}\text { Bilharzia } \\
\text { Don't know }\end{array}$ & 0 & $9(12.7)$ & $9(5.1)$ & $6(6.6)$ & $11(7.3)$ & $17(7.1)$ \\
\hline \multicolumn{7}{|l|}{ Have you ever heard about } \\
\hline Yes & $65(61.9)$ & $66(93)$ & $131(74.4)$ & $44(48.4)$ & $119(79.3)$ & $163(67.6)$ \\
\hline \multicolumn{7}{|l|}{ No } \\
\hline \multicolumn{7}{|l|}{ Does Bilharzia affect all age } \\
\hline Yes & $0(0)$ & $0(0)$ & $0(0)$ & $1(2.1)$ & $2(6.5)$ & $3(3.8)$ \\
\hline No & $6(15)$ & $1(20)$ & $7(15.6)$ & $1(2.1)$ & $4(12.9)$ & $5(6.4)$ \\
\hline \multicolumn{7}{|l|}{ Don't know } \\
\hline \multicolumn{7}{|l|}{ Source of infection } \\
\hline Water & $36(90)$ & $4(80)$ & $40(88.9)$ & $39(83)$ & $17(54.8)$ & $56(71.8)$ \\
\hline Poor sanitation & $0(0)$ & $0(0)$ & $0(0)$ & $1(2.1)$ & $1(3.2)$ & $2(2.6)$ \\
\hline Contagious & $0(0)$ & $0(0)$ & $0(0)$ & $2(4.3)$ & $0(0)$ & $2(2.6)$ \\
\hline Air & $0(0)$ & $0(0)$ & $0(0)$ & $0(0)$ & $1(3.2)$ & $1(1.3)$ \\
\hline Mosquito bite & $0(0)$ & $0(0)$ & $0(0)$ & $1(2.1)$ & $0(0)$ & $1(1.3)$ \\
\hline Don't know & $4(10)$ & $1(20)$ & $5(11.1)$ & $4(8.5)$ & $12(38.7)$ & $16(20.5)$ \\
\hline \multicolumn{7}{|l|}{ Mode of transmission } \\
\hline Water contact (washing, & $27(75)$ & $1(20)$ & $28(70)$ & $20(51.3)$ & $14(82.4)$ & $34(60.7)$ \\
\hline bathing or swimming) & $17(47.2)$ & $3(60)$ & $20(44.4)$ & $23(59)$ & $6(35.3)$ & $29(51.8)$ \\
\hline $\begin{array}{l}\text { Drinking water and } \\
\text { washing or swimming } \\
\text { Don't know }\end{array}$ & $4(11.1)$ & $1(20)$ & $5(12.5)$ & $2(5.1)$ & $5(29.4)$ & $7(12.5)$ \\
\hline \multicolumn{7}{|l|}{ Frequent water contact $(n=40$} \\
\hline$\& 56)$ & $35(97.2)$ & $4(100)$ & $39(97.5)$ & $39(100)$ & $16(94.1)$ & $55(98.2)$ \\
\hline Yes & $1(2.8)$ & $0(0)$ & $1(2.5)$ & $0(0)$ & $1(5.9)$ & $1(1.8)$ \\
\hline No & & & & & & \\
\hline \multicolumn{7}{|l|}{ Knowledge of the vector } \\
\hline Yes & $1(2.8)$ & $0(0)$ & $1(2.5)$ & $3(7.7)$ & $3(17.6)$ & $6(10.7)$ \\
\hline No & $35(97.2)$ & $4(100)$ & $39(97.5)$ & $36(92.3)$ & $14(82.4)$ & $50(89.3)$ \\
\hline
\end{tabular}


Thirteen subjects $(28.9 \%)$ from Dudicha and $40(51.3 \%)$ from Shesha Kekel mentioned that abdominal pain or bloody diarrhea is a common symptom of Bilharzia; out of whom, 20 (8 from Dudicha and 12 from Shesha Kekel) were positive for $S$. mansoni. Thirty-eight individuals $(84.4 \%)$ from Dudicha and 58(74.4\%) from Shesha Kekel said that Bilharzia has treatment; of whom $24(63.2 \%)$ subjects from Dudicha and $15(25.9 \%)$ subjects from Shesha Kekel were positive. Seven $(15.6 \%)$ individuals from Dudicha and $20(25.6 \%)$ from

Shesha Kekel had no information whether or not the disease has treatment. Thirty-eight individuals (84.4\%) from Dudicha and 44 (56.4\%) from Shesha Kekel knew that it is possible to prevent by giving treatment, using clean water for drinking and washing and reducing water contact (Table 3).

\section{DISCUSSION}

In Ethiopia, many studies have been done on the prevalence of schistosomiasis with very little emphasis on knowledge of the community about the disease (19). In this study, we attempted to assess awareness about intestinal schistosomiasis in two rural communities living in schistosomiasis endemic areas. The results showed that the overall awareness and knowledge of the disease in both communities was very low. Nearly one-third of the study subjects heard about biharzia despite the endemicity of the disease in the study areas $(14,16,20)$. Previous study conducted in Kemisie Town, northern Ethiopia, showed relatively high level of community awareness about intestinal schistosomiasis (19). The low level of awareness about schistosomiasis observed in the present study communities might be due to their rural settings as compared to higher awareness of the disease in Kemisie which is an Urban setting.

In the present study, both, individuals who experienced the symptoms of the disease and those who did not have the symptoms, were unaware of the disease. This indicates lack of awareness or knowledge about schistosomiasis which influences treatment-seeking behavior. A study conducted in Cameroon to determine the impact of health education intervention on the perception and prevalence of urinary schistosomiasis among schoolchildren in endemic rural communities showed a significant increase of awareness about the disease and a significant reduction of the prevalence of the disease within a short period of time after the implementation of the programme (22). Implementation of health education in the control of urinary schistosomiasis in Niger (23) and intestinal schistosomiasis (24) in Senegal also resulted in a significant increase in awareness about the diseases and treatment seeking behavior of the communities in both countries although the specific knowledge of the diseases and changes in behavior remained low.

Bilharzia was more common in those who had awareness about the disease in Dudicha. Similar findings in children who had more awareness about urinary schistosomiasis in Ghana raised the question why awareness did not result in low prevalence and avoidance of risk behavior (25). Study in Brazil has also shown that despite high awareness about the source and mode of transmission of schistosomiasis, people living in endemic areas do not avoid exposure because lack of other alternatives as well as low impact of the disease on their daily activities (9). Several factors such as socioeconomic status, cultural beliefs, lack of specific knowledge about the disease, age, religion and occupation might explain such findings (7). 
Table 3. Awareness about bilharzias, its symptoms, treatment and prevention, and the prevalence of infection among those respondents who provided stool samples, Dudicha and Shesha Kekel communities, June 2004.

\begin{tabular}{|c|c|c|c|c|c|c|c|c|c|c|c|c|}
\hline \multirow{3}{*}{ Variables } & \multicolumn{6}{|c|}{ Dudicha } & \multicolumn{6}{|c|}{ Shesha } \\
\hline & \multicolumn{3}{|c|}{ Respondents } & \multicolumn{3}{|c|}{ No. of positive } & \multicolumn{3}{|c|}{ Respondents } & \multicolumn{3}{|c|}{ No. of positive } \\
\hline & $\begin{array}{c}\mathrm{M}(\%) \\
\mathrm{N}=104\end{array}$ & $\begin{array}{l}\mathrm{F}(\%) \\
\mathrm{N}=65\end{array}$ & $\begin{array}{c}\mathrm{T}(\%) \\
\mathrm{N}=169\end{array}$ & $\mathrm{M}(\%)$ & $\mathrm{F}(\%)$ & $\mathrm{T}(\%)$ & $\begin{array}{l}\mathrm{M}(\%) \\
\mathrm{N}=88\end{array}$ & $\begin{array}{c}\mathrm{F}(\%) \\
\mathrm{N}=146\end{array}$ & $\begin{array}{c}\mathrm{T}(\%) \\
\mathrm{N}=234\end{array}$ & $\mathrm{M}(\%)$ & $\mathrm{F}(\%)$ & $\mathrm{T}(\%)$ \\
\hline \multicolumn{13}{|l|}{$\begin{array}{l}\text { Have you ever heard about } \\
\text { bilharzia? }\end{array}$} \\
\hline Yes & $40(38.5)$ & $5(7.7)$ & $45(26.6)$ & $24(60)$ & $4(80)$ & $28(62.2)$ & $47(53.4)$ & $31(21.2)$ & $78(33.3)$ & $17(36.2)$ & $7(22.6)$ & $24(30.8)$ \\
\hline No & $64(61.5)$ & $60(92.3)$ & $124(73.4)$ & $35(54.7)$ & $10(16.7)$ & $45(36.3)$ & $41(46.6)$ & $115(78.8)$ & $156(66.7)$ & 13(31.7) & $37(32.2)$ & $50(32.1)$ \\
\hline \multicolumn{13}{|l|}{$\begin{array}{l}\text { Have you/your family ever been } \\
\text { sick from bilharzia? } *\end{array}$} \\
\hline Yes & $20(50)$ & $1(20)$ & $21(46.7)$ & $13(65)$ & $1(100)$ & 14(66.7) & $22(46.8)$ & $10(32.3)$ & $32(41)$ & $10(45.5)$ & $3(30)$ & $13(40.6)$ \\
\hline No & $19(47.5)$ & $4(80)$ & $23(51.1)$ & $11(57.9)$ & $3(75)$ & 14(60.9) & $22(46.8)$ & $19(61.3)$ & $41(52.6)$ & $5(22.7)$ & $4(21.1)$ & $9(22)$ \\
\hline Don't know & $1(2.5)$ & $0(0)$ & $1(2.2)$ & $0(0)$ & $0(0)$ & $0(0)$ & $3(6.4)$ & $2(6.4)$ & $5(6.4)$ & $2(66.7)$ & $0(0)$ & $2(40)$ \\
\hline \multicolumn{13}{|l|}{ Symptoms of bilharzias* } \\
\hline pain/bloody & $12(30)$ & $1(20)$ & 13(28.9) & $7(58.3)$ & $1(100)$ & $8(61.5)$ & $27(57.4)$ & 13(41.9) & $40(51.3)$ & $11(40.7)$ & $1(7.7)$ & $12(30)$ \\
\hline diarrhea & $5(12.5)$ & $0(0)$ & $5(11.1)$ & $2(40)$ & $0(0)$ & $2(40)$ & $3(6.4)$ & $0(0)$ & $3(3.8)$ & 1(33.3) & $0(0)$ & 1(33.3) \\
\hline Weakness & $23(57.5)$ & $4(80)$ & $27(60)$ & $15(65.2)$ & $3(75)$ & $18(66.7)$ & $17(36.2)$ & $18(58.1)$ & $35(44.9)$ & $5(29.4)$ & $6(33.3)$ & 11(31.4) \\
\hline Don't know & & & & & & & & & & & & \\
\hline \multicolumn{13}{|l|}{ Does bilharzia have a treatment* } \\
\hline Yes & $35(87.5)$ & $3(60)$ & $38(84.4)$ & $21(60)$ & $3(100)$ & $24(63.2)$ & $38(80.9)$ & $20(64.5)$ & 58(74.4) & 13(34.2) & $2(10)$ & $15(25.9)$ \\
\hline No & $0(0)$ & $0(0)$ & $0(0)$ & $0(0)$ & $0(0)$ & $0(0)$ & $0(0)$ & $0(0)$ & $0(0)$ & $0(0)$ & $0(0)$ & $0(0)$ \\
\hline Don't know & $5(12.5)$ & $2(40)$ & $7(15.6)$ & $3(60)$ & $1(50)$ & $4(57.1)$ & $9(19.1)$ & $11(35.5)$ & $20(25.6)$ & $4(44.4)$ & $5(45.5)$ & $9(45)$ \\
\hline \multicolumn{13}{|l|}{ Is it possible to prevent bilharzia } \\
\hline Yes & $35(87.5)$ & $3(60)$ & $38(84.4)$ & $20(57.1)$ & $3(100)$ & $23(60.5)$ & $30(63.8)$ & $14(45.2)$ & $44(56.4)$ & $10(33.3)$ & $2(14.3)$ & $12(27.3)$ \\
\hline No & $3(7.5)$ & $2(40)$ & $5(11.1)$ & $2(66.7)$ & $1(50)$ & $3(60)$ & $2(4.3)$ & $3(9.6)$ & $5(6.4)$ & $0(0)$ & $0(0)$ & $0(0)$ \\
\hline Don't know & $2(5)$ & $0(0)$ & $2(4.4)$ & $2(100)$ & $0(0)$ & $2(100)$ & $15(31.9)$ & $14(45.2)$ & $29(37.2)$ & $7(46.7)$ & $5(35.7)$ & $12(41.4)$ \\
\hline \multicolumn{13}{|l|}{ Preventive mechanisms ${ }^{* *}$} \\
\hline Treatment & $21(60)$ & $2(66.7)$ & $23(60.5)$ & $12(57.1)$ & $2(100)$ & 14(60.9) & $14(46.7)$ & $7(50)$ & $21(47.7)$ & 4(28.6) & $1(14.3)$ & $5(23.8)$ \\
\hline Drinking clean water & $10(28.6)$ & 0 & $10(26.3)$ & $5(50)$ & 0 & $5(50)$ & $10(33.3)$ & $6(42.9)$ & $16(36.4)$ & $4(40)$ & 1(16.7) & $5(31.3)$ \\
\hline Reduce water contact & $3(8.6)$ & 0 & $3(7.9)$ & $2(66.7)$ & 0 & $2(66.7)$ & $3(10)$ & $4(28.6)$ & $7(15.9)$ & $1(33.3)$ & $0(0)$ & 1(14.3) \\
\hline Sanitation & 4(11.4) & 0 & $4(10.5)$ & $1(25)$ & 0 & $1(25)$ & $2(6.7)$ & $0(0)$ & $2(4.5)$ & $0(0)$ & $0(0)$ & $0(0)$ \\
\hline Killing snails & $0(0)$ & 0 & $0(0)$ & 0 & 0 & $0(0)$ & $2(6.7)$ & $1(7.1)$ & $3(6.8)$ & $1(50)$ & $0(0)$ & $1(33.3)$ \\
\hline Don't know & $0(0)$ & $1(33.3)$ & $1(2.6)$ & 0 & $1(100)$ & $1(100)$ & 0 & $0(0)$ & $0(0)$ & $0(0)$ & $0(0)$ & $0(0)$ \\
\hline
\end{tabular}

- Respondents were only those who had awareness, ** respondents were only those who said it is possible to prevent bilharzia, $\mathrm{M}=\mathrm{Male}, \mathrm{F}=\mathrm{Female}$ $\mathrm{T}=$ Total 
In conclusion, the present study showed that the majority of the people in the two study areas had low awareness about schistosomiasis although the disease was prevalent. Moreover, those few individuals who heard about the disease had limited knowledge about source of infection, mode of transmission and prevention methods. Although it may not be possible to avoid water contact activities and exposure to the parasite in the absence of other alternatives (7), we believe that provision of health education is useful as a strategy to raise community awareness of schistosomiasis as well as treatmentseeking behavior in such endemic areas.

\section{ACKNOWLEDGMENTS}

The authors would like to acknowledge community leaders and participants for their cooperation during the survey. We are also grateful to staff of Medical Parasitology Unit of the Institute of Pathobiology, Addis Ababa University, for their technical assistance. This work was financially supported by Howard University, MRIT program.

\section{REFERENCES}

1. Brinkmann UK, Korte R, Schmidt-Ehry B. The distribution and spreading of schistosomiasis in relation to water resources development in Mali. Trop Med Parasitol. 1988; 39: 182-185.

2. Chitsulo L, Engels D, Montresor A, Savioli L. The global status of schistosomiasis and its control. Act Trop. 2000; 77: 41-51.

3. Engels D, Chitsulo L, Montresor A, Savioli L. The global epidemiological situation of schistosomiasis and new approaches to control and research. Act Trop. 2002; 82: 139-146.

4. WHO. The control of schistosomiasis. WHO Techinical report series, 1993 ;830: 86.

5. Colley DG, Lo Verde PT, Savioli L. Medical helminthology in the $21^{\text {st }}$ century. Science. 2001; 293: 1437-1438.

6. WHO. Tropical Disease Research Progress 19751994. WHO Technical Report Series. Genva, 1995: 167.

7. Kloos H. Human behaviour, health education and schistosomiasis control: a review. Soc Sci Med. 1995; 40: 1497-1511.

8. Schall VT. An interactive perspective of health education for the tropical disease control: the schistosomiasis case. Memorias do Instituto Oswaldo Cruz, Rio de Janeiro, 1998; 93(suppl. 1): 51-58.

9. Gazzinelli A, Gazzinelli MF, Cadete MM, Pena Filho $\mathrm{S}$, Sa IR, Kloos H. Sociocultural aspects of schistosomiasis mansoni in an endemic area in
Minas Gerais, Brazil. Cad Saude Publica,1998; 14;841-849.

10. Useh MF, Ejezie GC. Modification of behaviour and attitude in the control of schistosomiasis. Observation on water-contact patterns and perception of infection. Annal Trop Med Parasitol. 1999; 93: 711-720.

11. Da Silva RA, De Carvalho ME, Zacharias F, R de Lima V, Teles H. Schistosomiasis mansoni in Bananal (State of Sao Paulo, Brazil). IV. Study on the public awareness of its risks in the Palha district. Memorias do Instituto Oswaldo Cruz, Rio De Janeiro. 2002; 97 (suppl.1): 15-18.

12. Ukwandu NCD, Nmorsi OPG. The perception, beliefs and practices toward genitourinary schistosomiasis by inhabitants of selected endemic areas (Edo/delta States) in south-eastern Nigeria. Rev Inst Med Trop S Paulo. 2004; 46: 2009-216.

13. Kloos H, Lemma A, Desole G. Schistosoma mansoni distribution in Ethiopia. A study in Medical Geography. Annal Trop Med Parasitol. 1978; 72: 461-470.

14. Ayele T, Tesfa-Yohannes TM. The epidemiology of Schistosoma mansoni around Lake Ziway and its islands, Ethiopia. Ethiop Med J. 1987; 25: 133-140.

15. Lo CT, Kloos H, Birrie H. Schistosomiasis in Zein ZA, Kloos H. The ecology of health and disease in Ethiopia. Ministry of Health Addis Ababa, 1988; pp. 196-213.

16. Jemaneh L. Schistosoma mansion and Geohelminthiasis in School children in the Dembia plains, Northwest Ethiopia. Ethiop J Health Dev. 1998; 12: 237- 244.

17. Erko B, Medhin G, Berhe N, Abebe F, Gebre-Michael T, Gundersen SG. Epidemiological studies on intestinal schistosomiasis in Wondo Genet, Southern Ethiopia. Ethiop Med J., 2002; 40: 29 - 38.

18. Erko B, Gebre-Michael T, Balcha F, Gundersen SG. Implication of Papio anubis in the transmission of intestinal schistosomiasis in three new foci in Kime area Ethiopia. Parasitol Int. 2001; 50: 259-266.

19. Tesfa-Michael T, Ayele T, Birrie H, Lo CT. Evaluation of Multidisciplinary control of schistosomiasis mansoni in a northern Ethiopian community.Institute of Pathobiology Research Report. 1987; 3: 17-29.

20. Roma B, Worku S. Magnitude of S. mansoni and intestinal helminthic infections among school children in Wondo Genet Zuria, Southern Ethiopia. Ethiop J Health Dev. 1997; 11: 125-129.

21.Peters PA, Ei Alamy M, Warren KS, Mahmoud AAF. Quick Kato smear for quantification of Schistosoma mansoni ova. Am J Trop Med Hyg. 1980; 29: 217.

22. Lucien KF, Nkwelang G, Ejezie GC. Health education strategy in the control of urinary schistosomiasis. Clin Laby Sci. 2003; 16: 137-141. 
23. Garba A, Aboubacar A, Barkire A, Vera C, Sellin B, Chippaux JP. Impact of health education programs on the control of urinary bilharziasis in Niger. Sante 2001; 11: 35-42.

24. Sow S, de Vlas SJ, Mbaye A, Polman K, Gryseels B. Low awareness of intestinal schistosomiasis in northern Senegal after 7 years of health education as part of intense control and research activities. Trop Med Int Health.2003; 8: 744- 752.

25. Wagatsuma Y, Aryeetey M.F, Nkrumah FK, Sack DA, Kojima S. Highly symptom-aware children were heavily infected with urinary schistosomiasis in southern Ghana. Centr Afr J Med. 2003; 49: 16-19. 